\title{
Geração Z: Infecções Sexualmente Transmissíveis (ISTs) recidivas e emergentes
}

\author{
Generation Z: Sexually Transmissible Infections (STIs) relapses and emerging \\ Generación Z: Infecciones Sexualmente Transmisibles (ITS) recurrencia y emergência
}

Recebido: 07/05/2021 | Revisado: 15/05/2021 | Aceito: 18/05/2021 | Publicado: 04/06/2021

Lucas Silva Mantovanelli

ORCID: https://orcid.org/0000-0002-5287-9710

Faculdade de Educação e Meio Ambiente, Brasil E-mail: lucasmantovanelli1997@gmail.com

Igor Gabriel da Silva

ORCID: https://orcid.org/0000-0002-2867-8513 Centro Universitário Católico Salesiano Auxilium, Brasil E-mail: igorgabriel.apple@icloud.com

Riole Leite da Silva

ORCID: https://orcid.org/0000-0001-7235-1887

Faculdade de Educação e Meio Ambiente, Brasil E-mail: riolle_leite@hotmail.com

Gilvan Barbieri de Almeida

ORCID: https://orcid.org/0000-0003-4432-6929

Faculdade Metropolitana UNNESA, Brasil

E-mail: gilvan_almeida15@hotmail.com

Thainara Araújo de Sousa

ORCID: https://orcid.org/0000-0001-5529-0939

Faculdade de Educação e Meio Ambiente, Brasil E-mail: thataaraujo_15@ hotmail.com

Silas Antônio Pereira

ORCID: https://orcid.org/0000-0003-0774-6465

Centro Universitário Católico Salesiano Auxilium, Brasil

E-mail: silasantonio1986@gmail.com

\begin{abstract}
Resumo
A geração Z é definida no meio social como a geração tecnológica, que incluem os nascidos entre os anos 1995 e 2010, pouco é falado desta geração ao se referir doenças, já que pata todas as patologias já se existe conhecimento científico, mas por se tratar de uma geração tão tecnológica, não se sabe se esses jovens estão tão cientes dos riscos. Esta pesquisa tem por objetivo geral retratar e relação da geração $\mathrm{Z}$ com o ressurgimentos de ISTs já erradicadas e com as emergentes, além de relatar o papel dos pais na sociedade atual. Como método de pesquisa, foi realizado análise da literatura bibliográfica de caráter descritivo, foram selecionados artigos da área das ciências da saúde. Por fim, conclui-se com a presente pesquisa que conhecer tecnologia não basta se não utilizá-la de maneira correta, e saúde sexual é mais importante que qualquer outro meio no que se trata de reduzir casos positivos para ISTs.
\end{abstract}

Palavras-chave: Adolescente; Doenças sexualmente transmissíveis; Doenças transmissíveis emergentes.

\begin{abstract}
Generation $\mathrm{Z}$ is defined in the social environment as the technological generation, which includes those born between the years 1995 and 2010, little is said about this generation when referring to diseases, since for all pathologies there is already scientific knowledge, but because it is of such a technological generation, it is not known whether these young people are so aware of the risks. The general objective of this research is to portray the relationship between generation $\mathrm{Z}$ and the resurgence of STIs already eradicated and with emerging ones, in addition to reporting the role of parents in today's society. As a research method, an analysis of the descriptive bibliographic literature was carried out, articles from the health sciences area were selected. Finally, it is concluded with this research that knowing technology is not enough if it is not used correctly, and sexual health is more important than any other means when it comes to reducing STI positive cases.
\end{abstract}

Keywords: Adolescent; Sexually transmitted diseases; Communicable diseases, emerging.

\section{Resumen}

La Generación Z se define en el ámbito social como la generación tecnológica, que incluye a los nacidos entre los años 1995 y 2010, poco se habla de esta generación al referirse a enfermedades, ya que para todas las patologías ya existe conocimiento científico, pero porque es de Para una generación tan tecnológica, no se sabe si estos jóvenes son tan conscientes de los riesgos. El objetivo general de esta investigación es retratar la relación de la generación $\mathrm{Z}$ con el resurgimiento de las ITS ya erradicadas y con las emergentes, además de informar sobre el papel de los padres en la 
sociedad actual. Como método de investigación se realizó un análisis de la literatura bibliográfica descriptiva, se seleccionaron artículos del área de ciencias de la salud. Finalmente, se concluye con esta investigación que conocer la tecnología no es suficiente si no se usa correctamente, y la salud sexual es más importante que cualquier otro medio a la hora de reducir los casos positivos de ITS.

Palabras clave: Adolescente; Enfermedades sexualmente transmisibles; Enfermedades transmisibles emergentes.

\section{Introdução}

A geração Z é definida no meio social como a geração tecnológica, que incluem os nascidos entre os anos 1995 e 2010, esta geração representa os jovens que já nasceram em meio à tecnologia e novas descobertas de informática. Pouco é falado desta geração ao se referir doenças, já que pata todas as patologias já se existe conhecimento científico, mas por se tratar de uma geração tão tecnológica, não se sabe se esses jovens estão tão cientes dos riscos (Teixeira, 2018).

São várias infecções sexualmente transmissíveis (ISTs) que surgem desde o ano de 1.509, de modo geral, para todas existe um tratamento e/ou cura ou retardamento, algumas delas até foram erradicadas, no entanto, ressurgiram nas últimas duas décadas. Qual seria a relação da geração $\mathrm{Z}$ com este fato? será que o conhecimento de tantas tecnologias interferem positivamente?

Acredita-se que a tecnologia não esteja sendo utilizada como se espera pela geração $Z$, pois, não é coincidência doenças emergentes surgir em meio ao surgimento deste novo grupo, e os pais que faziam um papel excelente na educação sexual de seus filhos da geração $\mathrm{Y}$ abandonaram este papel em meio a tanta tecnologia e informação.

Esta pesquisa tem por objetivo geral retratar e relação da geração $\mathrm{Z}$ com o ressurgimentos de ISTs já erradicadas e com as emergentes, além de relatar o papel dos pais na sociedade atual.

Com esta pesquisa, procuramos propor mecanismos de interferências para o controle de notificações por ISTs que podem ser erradicadas por simples ações, contribuindo positivamente com a saúde pública.

\section{Metodologia}

Como método de pesquisa, foi realizado análise da literatura bibliográfica de caráter descritivo, foram selecionados artigos da área das ciências da saúde postados em revistas via internet como o site Scielo e Medcline. Como critérios de inclusão foram artigos que tratavam do tema proposto, enfatizando geração $\mathrm{Z}$ com o aumento do número de infectados por doenças de transmissão sexual, postados entre os anos de 2017 e 2021.

\section{Resultados e Discussão}

\subsection{História}

A primeira Doença Sexualmente Transmissível (DST) surgiu na Itália por volta do ano de 1.509, o primeiro a manifestar sintomas foi um jovem soldado alemão que sofreu com a doença por 10 anos, questionando haver furúnculos e cheiro ruim, esta doença com o passar dos anos se tornou uma epidemia responsável pela morte de milhares de pessoas, principalmente jovens (Bueno, 2018). Apenas em 1645 foi descoberta a doença e forma de contágio, foi chamada de sífilis (Almeida, 2017).

Em novembro de 2016, o Departamento de Vigilância, Prevenção e Controle das DST, do HIV/Aids e das Hepatites Virais, substituiu a nomenclatura DST para Infecção Sexualmente Transmissível (IST), justificando o fato de que o termo "doença" implica sinais e sintomas evidentes no organismo, já o termo "infecção" se refere à períodos sem sintomas (Pereira, 2019). 


\subsection{Geração Z}

Segundo Campeiz (2017), o termo geração Z pode ser definido sociologicamente como a geração de jovens nascidos entre os anos de 1995 à 2010, de maneira geral, essa geração é marcada como jovens tecnológicos, já que convivem em meio a tecnologia e novas descobertas. Outra característica marcante desse grupo é a maneira como facilitam as coisas e simplificam problemas sociais, muitas das vezes, sem pensar em conseqûencias (Rech, 2017).

\subsection{ISTs emergentes e recidivas}

ISTs emergentes é a nomenclatura dada aquelas que surgem através da consequência de algo ou de alguma ação, as recidivas são as que já surgiram e foram erradicadas e, tornaram a serem notificadas (Koerich, 2019).

Como ISTs emergentes, podemos citar vários, dentre eles, as mais comuns são: cancro mole, gonorreia e herpes genital. Como recidivas, as principais são: sífilis, tricomoníase e vaginose bacteriana (Gomes, 2019).

\subsubsection{Cancro mole (Figura 1)}

Causado pela bactéria Haemophilus ducreyi, causa feridas dolorosas e múltiplas com tamanho pequeno e presença de pús, aparecem com maior frequência nos órgãos genitais, podendo também, surgir caroços e ínguas (Formozo, 2019).

Figura 1 - Cancro mole.
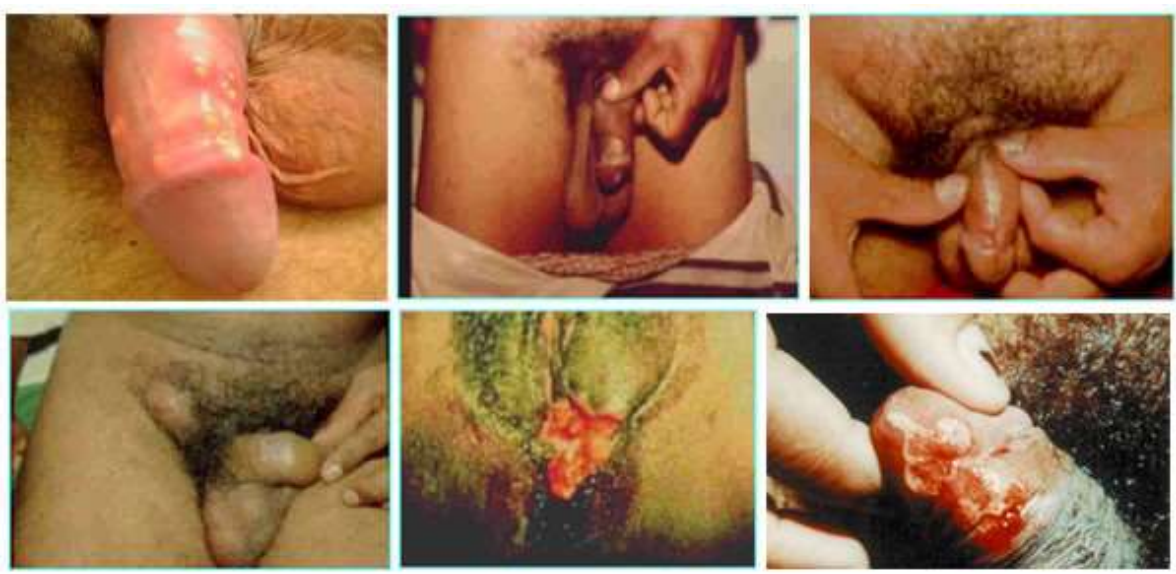

Fonte: OMS (2018).

\subsubsection{Gonorreia (Figura 2)}

Causada pela bactéria Neisseria gonorrhoeae, atinge órgão genitais, olhos e garganta, se não tratada causa infertilidade e dor durante relações sexuais, como sintomas incluem dor ao urinar, corrimento amarelado e/ou sangramento (Britto, 2018). 
Figura 2 - Gonorreia.

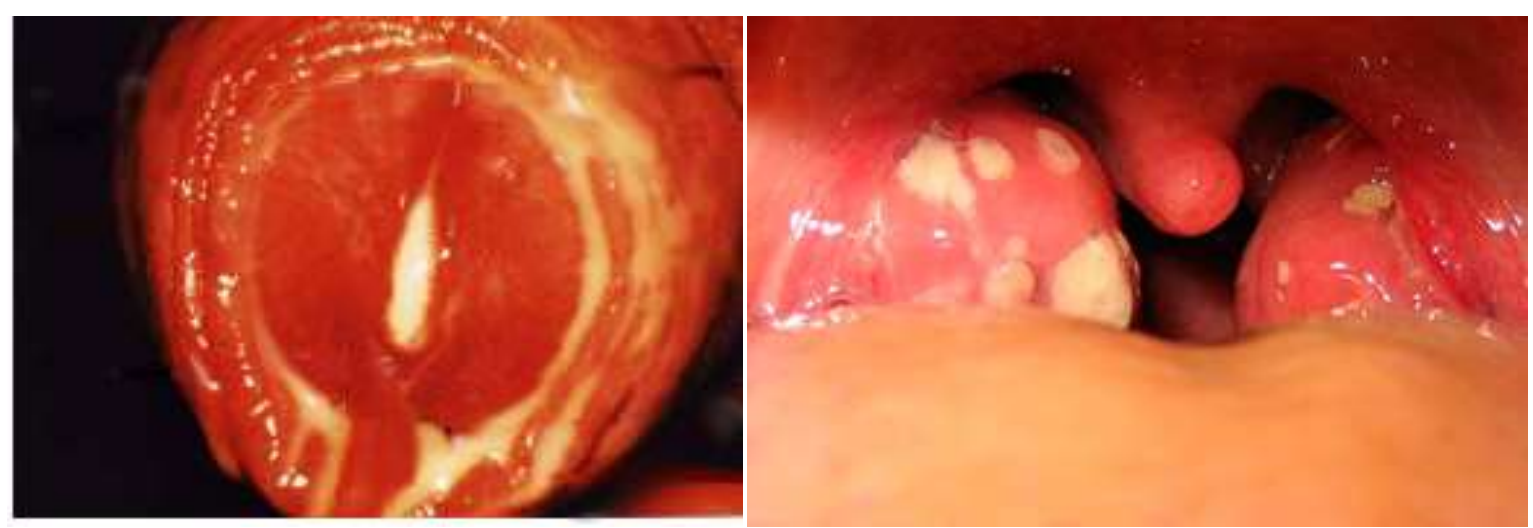

Fonte: OMS (2018).

\subsubsection{Herpes genital (Figura 3)}

A herpes genital é causada pelo vírus do herpes simples (HSV), sinais e sintomas aparecem em seis dias após a infecção e desaparecem após três semanas, incluem formigamento, coceira, ardor, dor muscular, febre, o que pode fazer que esta infecção passe despercebida (Peñagajate, 2020).

Figura 3 - Herpes genital

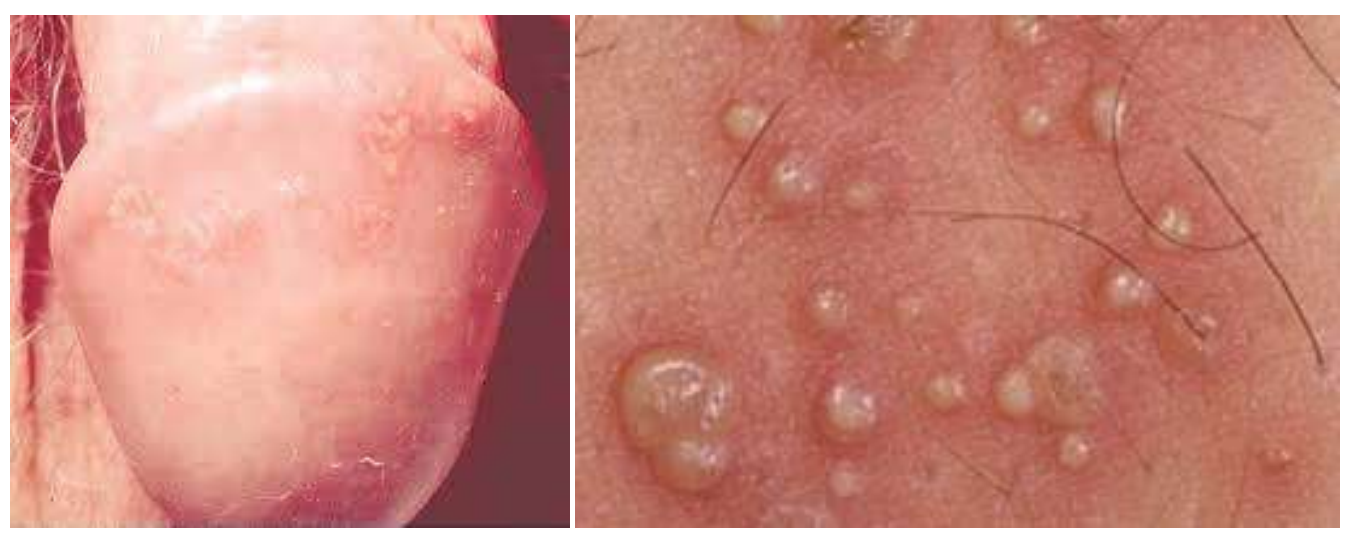

Fonte: OMS (2019).

\subsubsection{Sífilis (Figura 4)}

Segundo Cavalcante (2017), a sífilis é causada pela bactéria Treponema pallidum, apresentam três estágios de infecção, sendo o início da infecção haver risco de transmissão maior. Os sinais e sintomas incluem feridas arredondadas e pequenas não dolorosas que desaparecem sem requerer nenhum tratamento, podem ocorrer manchas no corpo que geralmente não coçam, febre, cefaleia e mal-estar (Vescovi, 2020). 
Figura 4 - Sífilis.

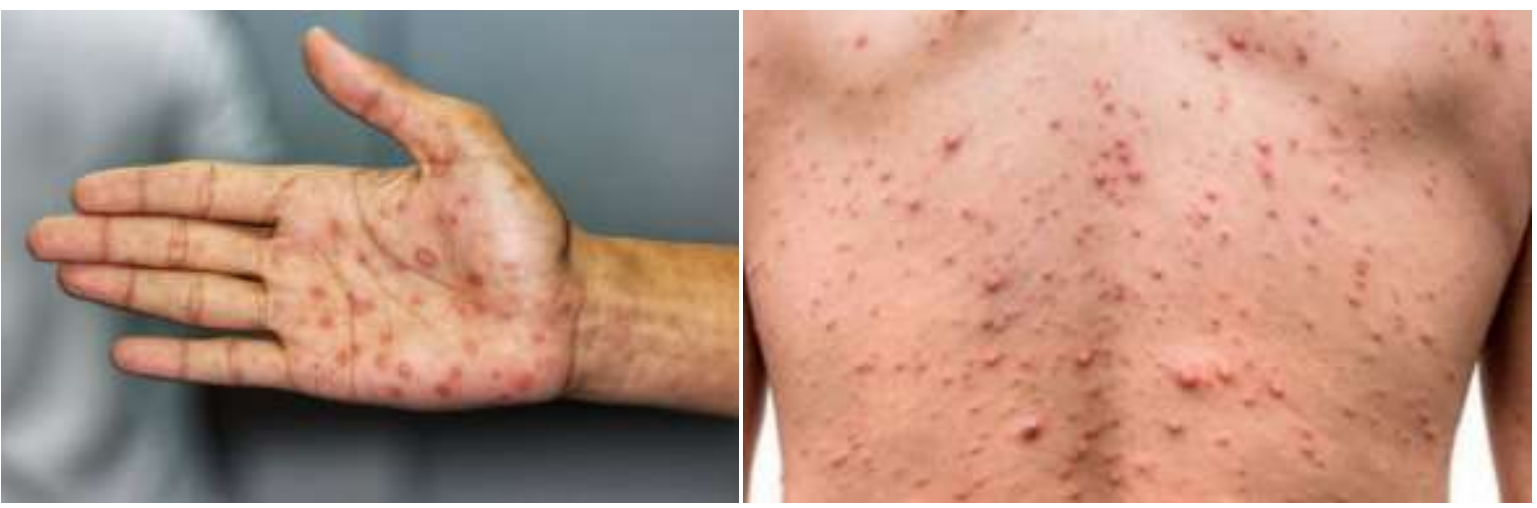

Fonte: OMS (2019).

\subsubsection{Tricomoníase (Figura 5)}

É uma infecção genital causada pelo protozoário Trichomonas Vaginalis, além da transmissão via sexual, ocorre também por meio do contato com a secreção, em geral, afeta mais mulheres que homens (De Sousa, 2021). Este protozoário causa microlesões na parte interna vaginal (Costa, 2021).

Figura 5 - Tricomoníase.

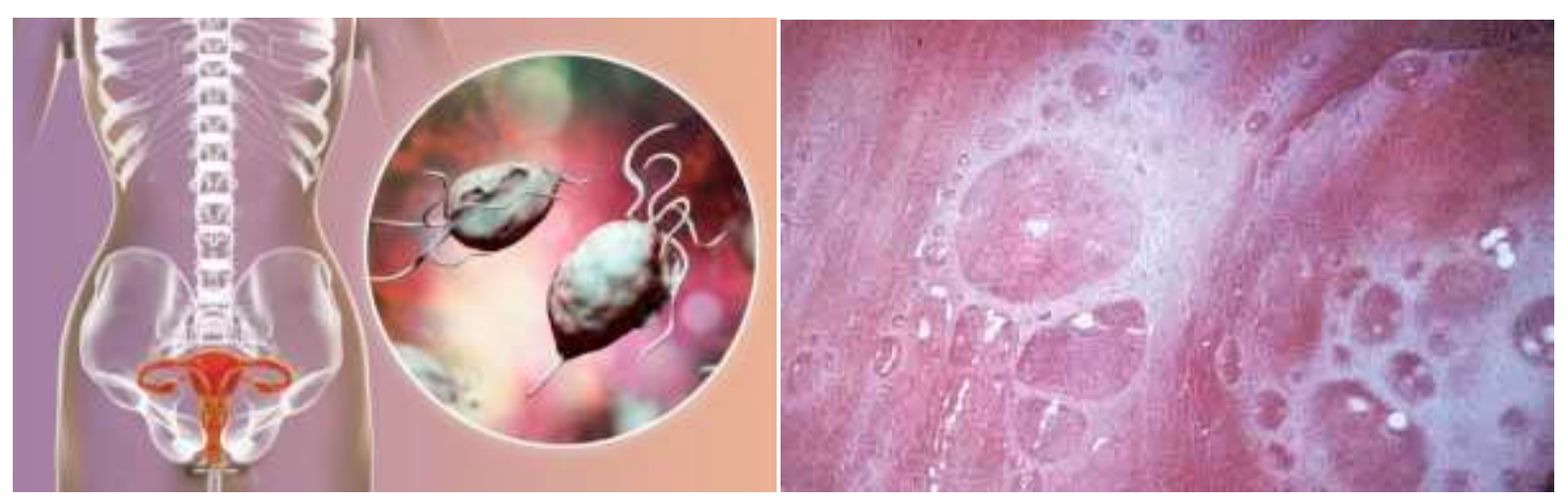

Fonte: OMS (2018).

\subsubsection{Vaginose bacteriana (Figura 6)}

É uma infecção vaginal causada por diversas bactérias, porém, é mais comum a infecção pela Gardnerella Vaginalis, esta infecção é a segunda maior causa de candidíase, já que desequilibra a flora vaginal (Mendling, 2017). Durante a menstruação, causa odor forte e desagradável. Como principais sintomas incluem corrimento branco-acinzentado e odor fétido (Ignácio, 2018). 


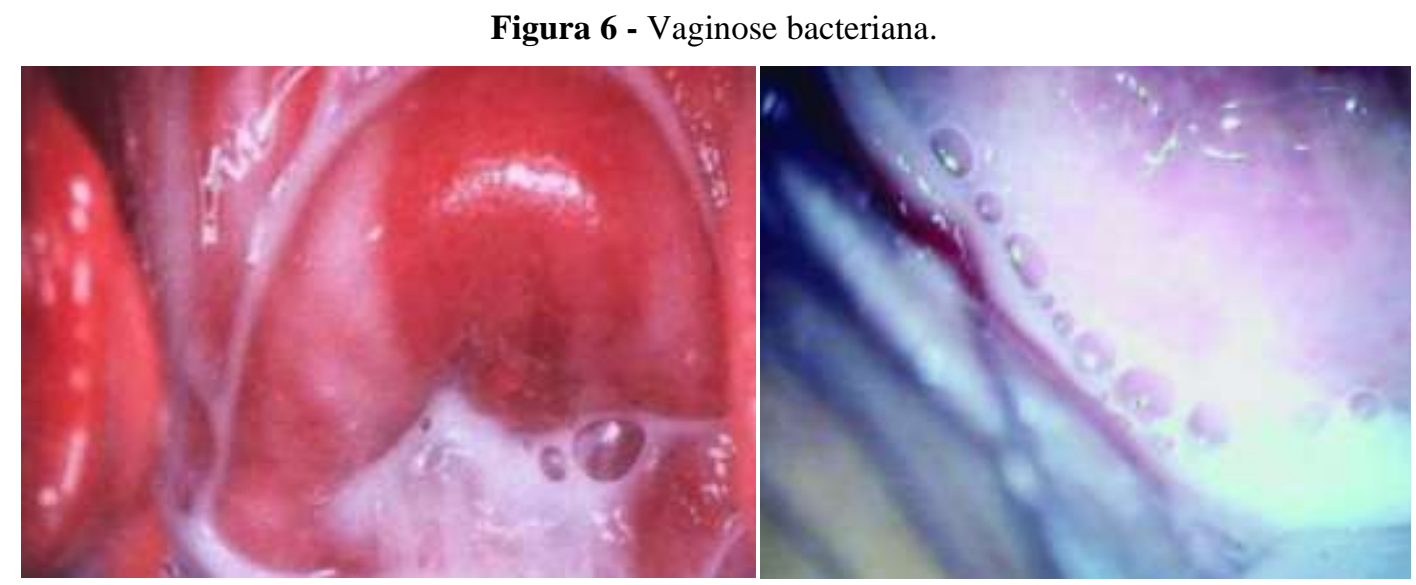

Fonte: OMS (2018)

\subsection{Relação entre geração Z e ISTs emergentes e recidivas}

Se tratando de uma geração tecnológica, acredita-se que estes jovens se sintam atraídos ao sexo vendo apenas sua forma de obtenção de prazer, fato este que omitem a si os riscos que o sexo desprotegido traz (Neves, 2017). Este é apenas um dos inúmeros problemas, podemos citar também o fato de que os pais deveriam ser mais presentes na vida sexual destes jovens, em meio a tantos caos, é comum que os pais se sintam intimidados ou envergonhados em conversar com seus filhos sobre sexo (Fonte, 2018).

De acordo com pesquisas, muitos jovens da geração $\mathrm{Z}$ relataram que não conversam com seus pais sobre sexo, foto preocupante, visto que nesse grupo social, o maior medo em relação ao sexo é ser pai ou mãe "cedo" (Wiedemann, 2019). Enquanto isso, doenças já esquecidas pela baixa notificação começaram a reincidir de acordos com dados do Ministério da Saúde (MS), além de novas infecções que ainda estão em fase de descoberta (Lannoy, 2021).

\section{Considerações Finais}

Esse estudo buscou relatar a importância do papel dos pais na redução do némero de casos de diagnósticos por infecções sexualmente transmissíveis. Foi possível diferenciar infecções emergentes e recidivas e citar as principais e suas formas sintomática.

A pesquisa constatou que são diversos fatores que justifiquem o porquê da geração $\mathrm{Z}$ estar diretamente inserida nos casos de ISTs emergentes e recidivas, dentre eles: o papel dos pais no falar sobre educação sexual.

Por fim, conclui-se com a presente pesquisa que conhecer tecnologia não basta se não utilizá-la de maneira correta, e saúde sexual é mais importante que qualquer outro meio no que se trata de reduzir casos positivos para ISTs.

\section{Referências}

Almeida, R. A. A. S. et al. (2017). Conhecimento de adolescentes relacionados às doenças sexualmente transmissíveis e gravidez. Revista Brasileira de Enfermagem. 70 (5).

Bueno, R. C. P., \& Ribeiro, P. R. M. (2018). História da educação sexual no brasil. Revista Brasileira de Sexualidade Humana. 29 (1).

Britto, A. M. A. et al. (2018). Detection of sexually transmitted infections at a Brazilian gynecology center: high prevalence of co-infections. Jornal Brasileiro de Patologia e Medicina Laboratorial. 54 (6).

Campeiz, A. F. et al. (2017). A escola na perspectiva de adolescentes da Geração Z. Revista Eletrônica de Enfermagem. 19

Cavalcante, P. A. M., Pereira, R. B. L., \& Castro, J. G. D. (2017). Sífilis gestacional e congênita em Palmas, Tocantins, 2007-2014. Epidemiologia e Serviços de Saúde. 26 (5).

Costa, I. M. V. et al. (2021). O papel da enfermagem na prevenção e controle da tricomoníase em mulheres. Revista Multidisciplinar em Saúde. 2 (1). 
Research, Society and Development, v. 10, n. 6, e40810615868, 2021

(CC BY 4.0) | ISSN 2525-3409 | DOI: http://dx.doi.org/10.33448/rsd-v10i6.15868

De Sousa, M. S. et al. (2021). Prevalência de tricomoníase e coinfecções em mulheres atendidas em dois centros de saúde em um município do Pará. Revista Eletrônica Acervo Saúde. 13 (3).

Fonte, V. R. F. da et al. (2018). Jovens universitários e o conhecimento acerca das infecções sexualmente transmissíveis. Escola Anna Nery. 22 (2).

Formozo, G. A. et al. (2019). Promoção da saúde e prevenção de IST: ações extensionistas numa abordagem dialógica em Macaé-RJ. Ministério da Educação Secretaria de Educação Profissional e Tecnológica Instituto Federal de Educação, Ciência e Tecnologia Fluminense 20 (9).

Gomes, S. S. S., \& Oliveira, M. G, R., J. L. P.(2019). Educação sexual no ensino médio: aula sobre métodos contraceptivos e ISTs. Pedagogia em Foco. 14 (12).

Ignácio, M. A. O. et al. (2018). Prevalência de vaginose bacteriana e fatores associados em mulheres que fazem sexo com mulheres. Revista Latino-Americana de Enfermagem. 26 (2).

Koerich, G. V., \& Cancellier, É. L. P. L. (2019). Frugal Innovation: origins, evolution and future perspectives. Cadernos EBAPE. 17 (4).

Lannoy, L. H. de et al. (2021). Protocolo Brasileiro para Infecções Sexualmente Transmissíveis 2020: infecções que causam corrimento uretral. Epidemiologia e Serviços de Saúde. 30 (26).

Mendling, W. (2017). Bakterielle Vaginose: von Dysbiose, Biofilmen und probiotischer Prophylaxe. gynäkologie e geburtshilfe. 22 (1).

Neves, R. G. et al. (2017). Simultaneidade de comportamentos de risco para infecções sexualmente transmissíveis em adolescentes brasileiros. Epidemiologia e Serviços de Saúde. 26 (44).

Peñagajate, L. et al. (2020). Herpes genital en un lactante. Hay que descartar abuso sexual en todos los casos?. Pediatría Atención Primaria. 22 (4).

Pereira, G. F. M et al. (2019). HIV/aids, hepatites virais e outras IST no Brasil: tendências epidemiológicas. 5 (7).

Rech, I. M, Viêra, M. M, \& Anschau, C. T. (2017). Geração z, os nativos digitais: como as empresas estão se preparando para reter esses profissionais. Revista tecnológica. $6(1)$.

Teixeira, A. D., \& De Oliveira, B. (2018). Geração Z: Problemáticas Do Uso Da Internet Na Educação Escolar. Ciclo Revista. 3 (1).

Vescovi, J. S., \& Schuelter-Trevisol, F. (2020). Aumento da incidência de Sífilis congênita no estado de Santa Catarina no período de 2007 a 2017 : análise da tendência temporal. Revista Paulista de Pediatria. 38 (2).

Wiedemann, R., \& Bohnet, S. (2019). Emergente Strukturen in der Wundversorgung. Zeitschrift für Gerontologie und Geriatrie. 52 (8). 